CUADERNOS DE ESTUDIOS GALLEGOS, LXVIII

Núm. 134 (enero-diciembre 2021), págs. 337-360

ISSN: $0210-847 \mathrm{X}$

https://doi.org/10.3989/ceg.2021.134.11

\title{
ORIGINAL Y COPIA DE UN GOYA. EL RETRATO DE CARLOS IV DEL ANTIGUO HOSPITAL REAL DE SANTIAGO DE COMPOSTELA
}

\author{
IVÁN REGA CASTRO \\ Universidad de León \\ ORCID iD: http://orcid.org/0000-0003-0348-1703 \\ ISIDRO PUIG SANCHIS \\ Universidad Politécnica de Valencia \\ ORCID iD: https://orcid.org/0000-0002-6381-5579
}

Copyright: (C) 2021 CSIC. La edición electrónica de esta revista se distribuye bajo los términos de una licencia de uso y distribución Creative Commons Reconocimiento 4.0 Internacional (CC BY 4.0).

Cómo citar/Citation: Iván Rega CASTRO, Isidro PuIG SANChIS, "Original y copia de un Goya. El Retrato de Carlos IV del antiguo Hospital Real de Santiago de Compostela", Cuadernos de Estudios Gallegos, 68, núm. 134 (2021), págs. 337-360, https://doi.org/10.3989/ceg.2021.134.11 


\section{ORIGINAL Y COPIA DE UN GOYA. EL RETRATO DE CARLOS IV DEL ANTIGUO HOSPITAL REAL DE SANTIAGO DE COMPOSTELA}

\section{RESUMEN}

Este estudio ofrece un avance importante en la identificación y documentación del proceso de copia pictórica en la serie de los retratos oficiales de Carlos IV, pintados por -o bajo supervisión de- Francisco de Goya entre 1789 y 1790. Los autores analizan uno de estos retratos, fechado en 1790, conservado en el ayuntamiento de Santiago de Compostela, y llevan a cabo el estudio comparativo - especialmente el dibujo subyacente- de este con otro retrato de Carlos IV, hasta ahora prácticamente desconocido, que es en verdad el primero de la serie.

Palabras Clave: Retrato del Carlos IV, serie de retratos oficiales, Francisco de Goya, dibujo subyacente, proceso de copia pictórica.

\section{ORIXINAL E COPIA DUN GOYA. O RETRATO DE CARLOS IV DO VELLO HOSPITAL REAL DE SANTIAGO DE COMPOSTELA}

\section{RESUMO}

Este estudo ofrece un avance importante na identificación e documentación do proceso de copia pictórica na serie de retratos oficiais de Carlos IV, pintados por-ou baixo a supervisión de- Francisco de Goya entre 1789 e 1790. Os autores analizan un destes retratos, datado en 1790, conservado no concello de Santiago de Compostela, e levan a cabo o estudo comparativo -especialmente o debuxo subxacente- deste outro retrato de Carlos IV, ata agora practicamente descoñecido, que en realidade é o primeiro da serie.

Palabras Clave: Retrato de Carlos IV, serie de retratos oficiais, Francisco de Goya, debuxo subxacente, proceso pictórico de copia.

\section{ORIGINAL AND COPY OF A PAINTING BY GOYA. THE PORTRAIT OF CARLOS IV FROM THE OLD ROYAL HOSPITAL IN SANTIAGO DE COMPOSTELA}

\section{ABSTRACT}

This study offers a major breakthrough in the identification and documentation of the copying process in the series of royal state portraits of Carlos IV, painted by -or under the supervision of- Francisco de Goya between 1789 and 1790. The authors analyse one of these portraits, dated from 1790, kept at Santiago de Compostela City Hall, and carry out a comparative study of this work -especially of the underlying drawing- with another thus far virtually unknown portrait of Carlos IV, which is in fact the first of the series.

KEY WORDS: Portrait of King Carlos IV, series of royal state portraits, Francisco de Goya, copying process, underlying drawing. 
Recibido/Received: 03/06/2020

Aceptado/Accepted: 01/11/2020

$\mathrm{E}$

n dependencias del Pazo de Raxoi, en la actual sede del Concello de Santiago, se conserva un retrato del Carlos IV (fig. 1) -depósito de la Diputación de A Coruña- ${ }^{1}$, cuya autoría fue motivo de polémica en los años 1930, tal como ventiló la prensa nacional y local.

Fue en julio de 1934 cuando el periodista de origen murciano Luis Benavente publicó, en un artículo del diario $A B C$-ilustrado con una fotografía del cuadro y un documento autógrafo-, la existencia de dicho retrato de Carlos IV en el antiguo Hospital Real y la "autenticidad de este Goya". En dicho artículo, Benavente reconocía la labor de investigación del periodista santiagués Celestino Sánchez Rivera y de una misteriosa "escritora inglesa miss Gallichan", a la cual atribuyó -injustamente- el hallazgo de un recibo a nombre de Francisco de Goya por el cuadro "de Su Magestad Reynante", fechado el 6 de marzo de 1790, por el cual percibió 2000 reales de vellón ${ }^{4}$.

Benavente empezaba el citado artículo lanzando una pregunta retórica: “¿Ha sido incluido en el catálogo completo de las obras de 'Don Francisco el de los

\footnotetext{
${ }^{1}$ Dejamos aquí constancia de nuestro agradecimiento al jefe del Servicio de Patrimonio de la Diputación de A Coruña, Luis J. Rodríguez, quien autorizó su estudio in-situ, en enero de 2015, y al Concello de Santiago de Compostela por facilitarnos el acceso. También a los profesores del Departamento de Historia da Arte de la Universidade de Santiago de Compostela, Enrique Fernández Castiñeiras y José Manuel B. López Vázquez, por su ayuda en la fase de estudio de campo; y a la conservadora del Museo de América, Rocío Bruquetas, por permitirnos acceder al estudio de los materiales y técnica pictórica del lienzo en cuestión llevado a cabo, en 1998, por el Instituto del Patrimonio Histórico Español (actual Instituto del Patrimonio Cultural de España). En último lugar, a Miquel Àngel Herrero Cortell, de la Universidad Politécnica de Valencia, por su impagable ayuda.

${ }^{2}$ Luís Benavente, "Un retrato y un autógrafo de Goya", $A B C$, [s/n.] (26-07-1934), págs. 6-7.

${ }^{3}$ Seguramente se refiere a la escritora y periodista británica Catherine Gasquoine Hartley (1866/671928), también conocida como Mrs. Walter M. Gallichan. No obstante, no hay ninguna referencia al particular en sus publicaciones dedicadas a Galicia: Catherine GASQuOINE HARTLEY (Mrs. Walter M. Gallichan), Spain revisited: a summer holiday in Galicia, London, Stanley Paul \& CO, 1911; y The story of Santiago de Compostela, London, J. M. Dent \& sons, 1td., 1912.

${ }^{4}$ El recibo desapareció tras hacerse público el hallazgo. Si bien ya se habían publicado -afortunadamente- sendas reproducciones en Benavente, "Un retrato...", pág. 6; Celestino SÁnchez Rivera, Notas Compostelanas. Historia. Tradiciones. Leyendas. Miscelánea, Santiago de Compostela, Libreria y Editorial Sucesores de Galí, s/f (h. 1945), pág. 243.
} 


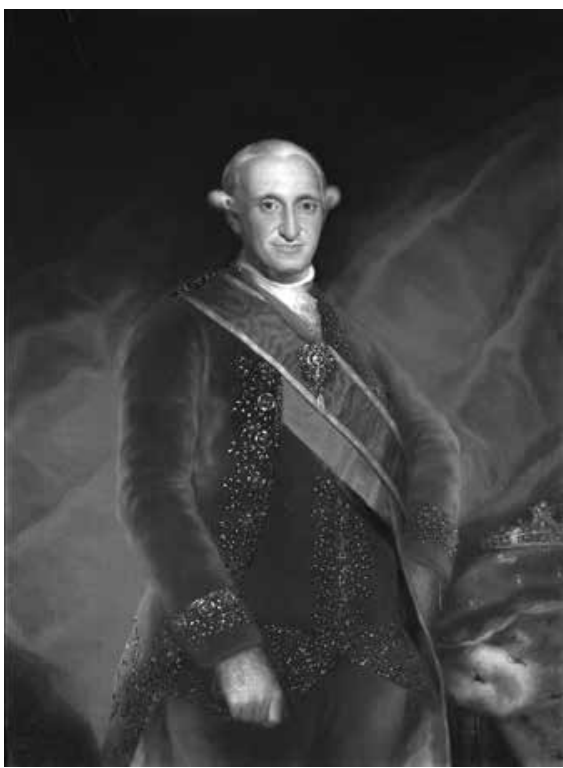

Fig. 1. Francisco de Goya (obrador), El rey Carlos IV, 126 x $94 \mathrm{~cm}$, óleo sobre lienzo, 1790, Diputación de A Coruña, depositado en el Pazo de Raxoi (Ayuntamiento de Santiago de Compostela), Santiago de Compostela.

(C) CAEM, Universitat de Lleida.

Toros' [Goya], el retrato de Carlos IV, comprobado como obra de aquél, [...], y existente en la sala Real del hospital de Santiago de Compostela?". La cual contestó vehementemente, después del verano de 1934, el mismo Sánchez Rivera en El Eco de Santiago -sin más datos-. Años más tarde, hacia 1945, Sánchez Rivera, en Notas Compostelanas, puntualizaba y cuestionaba la información aportada por Benavente, además de reivindicar la paternidad del hallazgo de la documentación y de la propuesta de autoría del cuadro en cuestión ${ }^{5}$.

Polémicas aparte, toda la literatura artística publicada hasta la fecha se hace eco, de forma mayoritaria, del artículo de Benavente ${ }^{6}$. Tras el hallazgo y publicación del recibo mencionado, son numerosos los especialistas que incluyeron este retrato de Carlos IV en el catálogo del pintor aragonés, desde J. Gudiol ${ }^{7}$; a veces sin prestarle la merecida atención al cuadro, y mucho menos a la disputa. Y no fue hasta la publicación del Catálogo del Patrimonio Artístico de la Diputación de A Coruña, en 1991, cuando finalmente se restituyó el mérito del descubrimiento a Sánchez Rivera.

En la ficha correspondiente al retrato de Carlos IV (núm. inv. 218), por entonces en el Museo Municipal de Santiago de Compostela, ya se indica que existen otros retratos casi idénticos y que estos "constituyen la serie tipológica de los retratos oficiales pintados por Goya. Sus diferentes calidades demuestran la participación de sus ayudantes en mayor o menor medida. En este caso el

\footnotetext{
5 SÁnCHEz Rivera, Notas Compostelanas..., págs. 241-246.

6 Valentín de SAmbricio, "Los retratos de Carlos IV y María Luisa, por Goya", Archivo Español de Arte, t. 30, núm. 118 (1957), pág. 88; José Gudiol, Goya: 1746-1828. Biografia, estudio analítico y catálogo de sus pinturas, vol. 4, Barcelona, Ediciones Polígrafa, 1970, pág. 280, cat. 289; Pierre GAssier y Juliet Wilson, Vida y obra de Francisco Goya: reproducción de su obra completa: pinturas, dibujos y grabados, Barcelona, Juventud, 1974, pág. 373; José CAmón AznAR, Fran. de Goya. Tomo II: 1785-1796, Zaragoza, Caja de Ahorros de Zaragoza, Aragón y Rioja, 1981, págs. 74-75, il.187; José Luis MorALES Y MARín, Las parejas reales de Goya. Retratos de Carlos IV y María Luisa de Parma, Zaragoza, Real Academia de Nobles y Bellas Artes de San Luis, 1997, pág. 20, cat. 5.

7 Gudiol, Goya..., vol. 4, pág. 280, cat. 289.
} 
rostro carente de fuerza y expresión - producto de una copia y no de un retrato al natural- así como el tratamiento de la indumentaria creemos demuestran la participación de su taller en la ejecución del retrato". Además, se hace hincapié en que "se ignoran cuales pudieron ser los originales de la amplia serie de retratos de medio cuerpo de Carlos IV y María Luisa de Parma atribuidos a Goya".

En efecto, su ejecución se basó en un ejemplar original que Francisco de Goya pintó de su mano, el cual, como se verá, sirvió de molde para una larga serie de retratos que se conservan en diferentes colecciones particulares, eclesiásticas y públicas españolas. Hasta ahora parecía bastante difícil averiguar, a través de un análisis formal y comparativo, cuál fue la cabeza de la serie ejecutada del natural por Goya y cuáles las réplicas, en las que intervinieron notablemente sus discípulos y colaboradores -siempre bajo supervisión del pintor-. No obstante, estas circunstancias podrían cambiar si prestásemos atención al estudio de los métodos y procedimientos utilizados para la copia pictórica -como expondremos a continuación $-y$, de un modo particular, a las evidencias procesuales que ofrecen las imágenes subyacentes, una cuestión escasamente trabajada tanto en el ámbito del taller de los pintores de corte, en general, como en la investigación técnica y procedimental sobre la obra del pintor aragonés, en particular.

Pero pasemos antes a repasar cuáles son esos retratos de Carlos IV que conservamos actualmente y que están perfectamente documentados como pintados, o mejor dicho, contratados por Francisco de Goya.

\section{GÉNESIS Y ORIGEN DE LA SERIE DE RETRATOS OFICIALES}

"No hay poder sin imagen, sin embargo, lo que lleva más tiempo componer es la imagen del poder" . No obstante, estas circunstancias no fueron precisamente las que se dieron en la creación del primer retrato oficial del nuevo rey, Carlos IV. Sambricio ya puso de relieve el hecho de que "el advenimiento al trono de Carlos IV y María Luisa de Parma por fallecimiento de Carlos III, acaecido en la madrugada del 14 de diciembre de 1788, señala un jalón trascendental en la vida y arte de Francisco de Goya" ${ }^{\text {. }}$. Habida cuenta de que inmediatamente

\footnotetext{
${ }^{8}$ María Luisa Sobrino y María Dolores Liaño (dir.), Catálogo del Patrimonio Artístico de la Diputación de A Coruña. I: Pintura y Escultura, A Coruña, Diputación Provincial, 1991, cat. 436, págs. 646-648.

9 José-Augusto FrançA, "O retrato na época joanina", en Joanni V Magnifico, A pintura em Portugal ao tempo de D. João V. 1706-1750 [catálogo de exposición], Lisboa, Instituto Português do Patrimônio Arquitectónico e Arqueológico, 1995, págs. 63-79, 97-107, esp. pág. 97. Cfr. José-Augusto FrançA, "Da imagem que falece ao poder: o retrato em Portugal no século XVIII", en Portugal no século XVIII de D. João Và revolução francesa, [congreso internacional organizado por la Sociedade Portuguesa de Estudos do século XVIII, Lisboa, 1990], Lisboa, Universitária Editora, 1991, págs. 19-26.

10 SAmbricio, "Los retratos de Carlos IV...”, pág. 85.
} 
después se dio inicio a un proceso destinado a crear el retrato oficial del nuevo rey, Carlos IV. Huelga decir cómo desde Lleida, una ciudad periférica, la corporación municipal de su Ayuntamiento se apresuraba a ordenar el pago de 1200 reales de vellón a su agente y apoderado en Madrid, D. Pedro Antonio Ferrari, "para costear el retrato de S. M. que se ha mandado hacer en Madrid", según acuerdo del 26 de enero de $1789^{11}$.

La necesidad de crear la imagen pública del rey y ofrecer un modelo para la retratística oficial del joven monarca era acuciante ya en las primeras semanas del reinado. De hecho, dos semanas después de la muerte de Carlos III, el Ayuntamiento de Madrid solicitó algunos modelos a Antonio Carnicero, como el conservado en el Museo Municipal de Madrid (inv. 24466), que copia el prototipo del retrato del anterior, realizado por Anton R. Mengs. Otros pintores, como Francisco Bayeu, también se propusieron crear una imagen que pudiera convertirse en retrato oficial, aunque sin mucho éxito. Numerosas instituciones encargaron pinturas del monarca, con desiguales fortunas ${ }^{12}$. Es probable que, en estas circunstancias, Goya empezara a idear su modelo y diseñar la que estaba llamada en convertirse en la imagen pública del rey. Sin duda, el trabajo de esbozado de un modelo o matriz era un proceso lento, meditado y reflexivo, puesto que a partir de una imagen original e individual del joven monarca, muchas otras habrían de pintarse, ajustándose siempre al primer ejemplar o prototipo. Lo que hacía de la fabricación de la imagen del rey un proceso complejo en el que artista y modelo podían chochar, ya que el retrato debía satisfacer a partes iguales, al Rey, que quería ver reflejada su "representación del yo" en el ámbito público ${ }^{13}$, su imagen pública -y por tanto, oficial-, y al pintor, que debía sacar partido de esta tarea en beneficio de su propia carrera.

En efecto, se trató de un proceso meditado, complejo, y lento, como cabía esperar. Así se colige, por ejemplo, de los gastos ordinarios de 1789, de la "Memoria de los géneros de Pintura, Bastidores y demás que yo D. Manuel Ezquerra y Trápaga he entregado a D. Francisco de Goya, pintor de cámara de S.M.C. (que Dios guarde) para los retratos de SS.MM. y demás obras que está ejecutando [...]", en que se recogen una serie de materiales encargados por Goya en diversas fechas. En un primer pedido, fechado el 9 de enero de 1789, aparece reflejados,

\footnotetext{
11 Archivo Municipal de Lleida, Libro de Albaranes de la Ciudad de Leyda de 30 de junio, 1781, en adelante, f. 79 .

12 José Manuel De la Mano, "Goya versus Bayeu: de la Proclamación a la Exaltación de Carlos IV", en Francisco Bayeu y sus discípulos [catálogo de exposición], Zaragoza, Cajalón, 2007, págs. 136-139.

13 Naturalmente, tomamos prestado el concepto de Erving GofFMAN, La presentación de la persona en la vida cotidiana, Buenos Aires; Madrid, Amorrortu; S. C. A, 2006 [primera edición en inglés, 1959], pág. 11. Este fue asociado al arte del retrato por Peter BuRKe, La Fabricación de Luis XIV, Madrid, Nerea, 1995, págs. 11-21, esp. pág. 19 y del mismo autor: Visto y no visto. El uso de la imagen como documento histórico, Barcelona, Crítica, 2001, págs. 37-43, esp. pág. 38.
} 
entre otros muchos materiales, "dos bastidores para los retratos de medio cuerpo" del rey, para dar inicio a los retratos oficiales de Carlos IV y a su esposa, María Luisa de Parma, y un lienzo de "Sn. Jorge para quadros", que es una tela gruesa, seguramente destinada a estos dos retratos y otros de cuerpo entero -a tenor de los documentados "dos bastidores de ocho pies de alto y cinco de ancho que se hicieron para los retratos de cuerpo entero" ${ }^{-14}$. José de la Mano, con buen criterio, sugiere que durante los primeros meses de 1789 Goya estaría esbozando el retrato oficial, y que "con toda probabilidad la composición originaria correspondería a la transcrita en los retratos de tres cuartos que se reproducirían con destino a la capital hispalense", en referencia a los retratos actualmente de la Colección Altadis. Incluso considera posible que entre febrero y marzo de 1789 Goya fuera al Palacio Real nuevo a retratar "del natural" a los nuevos monarcas, o por lo menos antes del 21 de abril, en que la familia real y su séquito se dirigieron hacia el Palacio Real de Aranjuez. Además, suscribimos las palabras de José de la Mano cuando sostiene que en el nuevo retrato de Carlos IV Goya demuestra su genialidad "en la coyuntura de interpretar pictóricamente en clave ilustrada los intereses propagandísticos de la monarquía hispana" ${ }^{15}$.

Así las cosas, desde principios de 1789, casi con toda seguridad, Goya se encontraba trabajando en una serie de retratos de los monarcas; la primera vez que el pintor aragonés retrataría a Carlos IV y a su esposa, pues no consta que los hubiera retratado siendo príncipes. Y es posible que, por sus medidas, los dos retratos de cuerpo entero citados anteriormente sean los conservados en el Museo del Prado (Inv. P03224, P02862) ${ }^{16}$.

Por tanto, ese denominado "prototipo originario", "retrato inaugural", "original perdido" o "escurridizo prototipo", fue ejecutado entre febrero y abril de 1789, y constituye un magnífico boceto -en el sentido de un apunte general- o prototipo que es, en verdad, la cabeza de serie para todos los retratos del Rey y grabados posteriores. A partir de este retrato se realizaron numerosas copias en calco, exactamente iguales en las dimensiones de la figura, y en las que únicamente se modificaban el color de la vestimenta, las dimensiones del lienzo y el aparato que los acompañaba -cortinajes, mesa, corona, etc.-, incluso en los retratos de cuerpo entero.

\footnotetext{
14 Valentín de SAmbricio, Tapices de Goya, Madrid, Patrimonio Nacional, 1946, págs. XC-XCII, docs. núms. 124-126.

15 José Manuel De la Mano, "Hacia las parejas reales de Goya. Evolución de la iconografía oficial de Carlos IV y María Luisa de Parma a través de sus pintores de cámara", en Carlos IV. Mecenas y coleccionista [catálogo de exposición], Madrid, Patrimonio Nacional; Sociedad Estatal de Conmemoraciones Culturales, 2009, pág. 83.

16 Sambricio, "Los retratos de Carlos IV...”, pág. 88. Véase también al respecto a DE LA Mano, "Goya versus Bayeu...”, págs. 149-150.
} 
En cuanto a las diversas réplicas o copias que salieron del taller de Palacio, sabemos por la Descripcion de los ornatos públicos con que la Corte de Madrid ha solemnizado la feliz exâltacion al trono de los reyes nuestros señores Don Carlos III [Carlos IV, Rey de España], y Doña Luisa de Borbon (1789) de la existencia de tres parejas de retratos realizados por Goya ${ }^{17}$. Una de estas parejas decoró, efectivamente, la fachada de la casa palacio del Conde de Campomanes, don Pedro Rodríguez de Campomanes, situada en la plaza de la Villa, donde en un balcón y protegidos bajo un dosel se situaron "los retratos de SS.MM pintados por Don Francisco Goya, pintor de Cámara de S. M. y Teniente Director de la Real Academia de San Fernando". Así pues, estos cuadros se identifican tradicionalmente con los conservados en la actualidad en la Real Academia de la Historia, ya que el Conde de Campomanes era, por entonces, Director de la institución. No obstante, estos retratos están perfectamente documentados, ya que la Academia los encargó al pintor aragonés, según consta en un recibo del 11 de septiembre de 1789, firmado por el propio Goya, en el que se lee: "Los retratos de SS. MM. Dn. Carlos IV y Da. Luisa de Borbón, pintados por Dn. Franco de Goya, su pintor de Cámara, para la Rl. Academia de la Historia, del tamaño del natural, y de más de medio cuerpo con las insignias reales, importan; 6000 rr. vn." 18 .

Siguiendo con esta serie o grupo, cabe citar los retratos de Carlos IV y la reina María Luisa encargados por los trabajadores de la Real Fábrica de Tabacos de Sevilla, con motivo de la visita de los monarcas a la ciudad, en agosto de 1789 . Se trata de la pareja de retratos actualmente propiedad de la Colección Altadis, y que fueron depositados en el Archivo General de Indias, en Sevilla (fig. 2) ${ }^{19}$.

Otra réplica, en que Carlos IV viste casaca azul de terciopelo forrada de raso blanco, ingresó en el Museo del Prado en 1911 (P07103), procedente del Ministerio de Hacienda. Estuvo en depósito, con su pareja, en el Museo de San Telmo de San Sebastián y, desde 1972, en el Museo de Bellas Artes de Zaragoza. También adquirió el Museo del Prado, en 1911 (P07107), otro retrato que estuvo en la Casa de la Moneda, el cual custodió el Museo de Bellas Artes de Córdoba entre 1931 y 1983, pasando luego al Museo Víctor Balaguer de Vilano-

\footnotetext{
17 Juan Sempere y Guarinos, Descripción de los ornatos públicos con que la Corte de Madrid ha solemnizado la feliz exaltación al trono de los reyes ... Don Carlos IIII y Doña Luisa de Borbón, y la jura del Serenísimo Señor Don Fernando, Príncipe de Asturias, Madrid, Imprenta Real, 1789, ff. 2, 5, y 50 respectivamente.

${ }_{18}$ Morales y Marín, Las parejas reales de Goya..., págs. 16-18, cat. 1; Herbert GonzÁlez Zymla, Catálogo de pinturas de la Real Academia de la Historia, Madrid, Real Academia de la Historia, 2003, cat. 43, págs. 106-111.

19 José M. Rodríguez Gordillo, José Morales SÁnchez y Alfonso E. Pérez SÁnchez, Goya. Retratos para la Real Fábrica de Tabacos de Sevilla, Madrid, Tabapress para Tabacalera S. A., 1985, pág. 24. Recibo de Goya del 11 de mayo de 1789.
} 


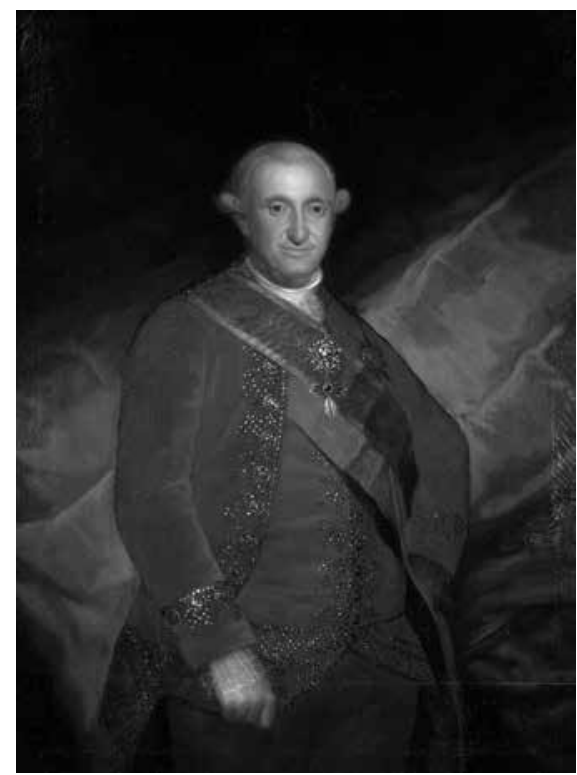

Fig. 2. Francisco de Goya (obrador), Carlos $I V, 128 \times 95,5 \mathrm{~cm}$, óleo sobre lienzo, 1789, Colección Altadis, depositado en el Archivo General de Indias, Sevilla. (C) CAEM, Universitat de Lleida. va i la Geltrú (Barcelona), donde se encuentra actualmente (fig. 3). Este, y su pareja, están bien documentados, pues consta en una Real Orden del 5 de enero de 1790 que: "El Rey ha resuelto que de los fondos de esa Casa [Casa de la Moneda de Madrid] se abonen a Don Francisco Goya los 4000 reales de vellón, importe de los dos retratos de medio cuerpo de S. M. y la Reyna N. Sra. Para el Tribunal de esa Casa ${ }^{20 "}$.

Poco después, el 3 de marzo en 1790 , se fecha un pago de la Tesorería General conforme al cual "El Rey manda qe. por Tesorería mayor y en virtud de su recivo se entreguen al Pintor dn. Franco. Goya dos mil rs. de vellon qe. ha costado un retrato de SM. de medio cuerpo que se ha puesto en esta Secreta. de Hacienda de mi cargo y es copia del original qe. hizo el mismo Goya; De orden de SM. lo

prevengo á V.S. para su cumplimto". Es de gran interés la noticia, habida cuenta de que refleja con toda claridad que se ejecutaron diferentes copias o réplicas del retrato del monarca a partir "del original qe. hizo el mismo Goya". La documentación constata, por lo tanto, la existencia de un original o prototipo de retrato oficial ejecutado por el pincel de Goya, y que sirvió de modelo o primer molde en que se fabricaron posteriormente todo este grupo de efigies del Rey. Esta orden de pago se ha relacionado, sin embargo, con el retrato que ingresó en el Museo del Prado en 1911, anteriormente citado y procedente del Ministerio de Hacienda (Inv. P07102) (fig. 4) ${ }^{21}$.

Otra pareja de retratos de los monarcas fue realizada por Goya para los duques de Osuna, según el recibo autógrafo del pintor, fechado el 27 de febrero de 1790 y en él se afirma que "Se han pintado de orden de los Excmos. Sres. Duques de Osuna, Condes de Benabente, etc., dos retratos de Nuestros Augustos

\footnotetext{
20 SAmbricio (comis.), Exposición Francisco de Goya. IV..., pág. 98.

${ }^{21}$ De la Mano, “Goya versus Bayeu...”, pág. 151. Archivo General de Palacio (AGP), Madrid, Carlos IV (Casa), leg. 178, caja 2.
} 


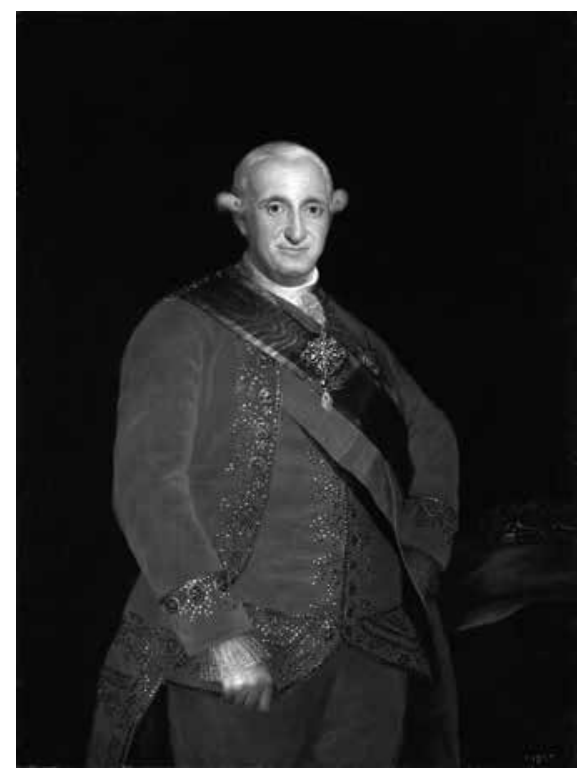

Fig. 3. Francisco de Goya (obrador), Carlos IV, rey de España, 27 x $94 \mathrm{~cm}$, óleo sobre lienzo, 1790, Museo del Prado (P07107), actualmente depositado en el Museu Víctor Balaguer, de Vilanova i la Geltrú (Barcelona). C Museo Nacional del Prado.

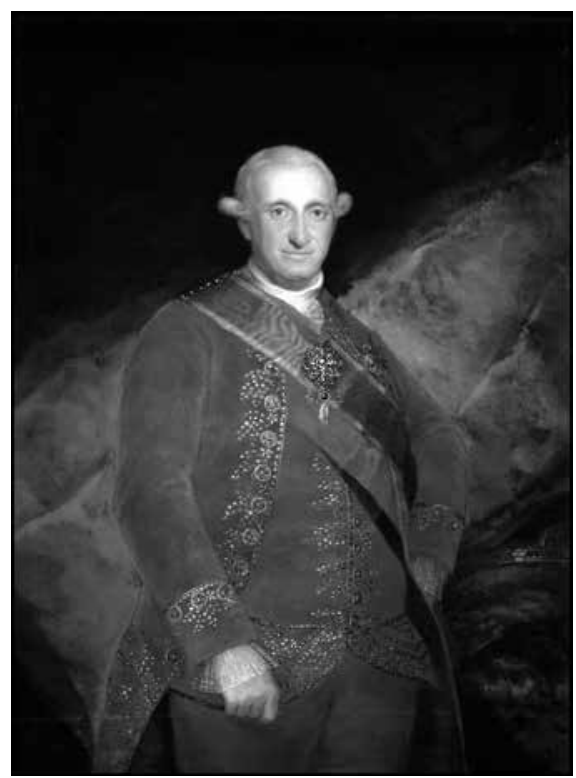

Fig. 4. Francisco de Goya (obrador), El rey Carlos IV, de rojo, 127,3 x 94,3 cm, óleo sobre lienzo, 1789, Museo del Prado, Madrid

(P07102). C Museo Nacional del Prado.

reyes para las funciones de su coronación, en óvalo de más de medio cuerpo, su valor quatro mil rr."22. Retratos, estos, cuyo paradero actual desconocemos ${ }^{23}$.

Y, por último, en orden cronológico, cabe citar el mencionado retrato realizado para el antiguo Hospital Real de Santiago de Compostela, el cual de alguna manera cierra esta serie. También consta recibo autógrafo, con fecha de 6 de marzo de 1790, el cual certifica que Goya recibió “[...] de D. Vicente Vázquez del Viso [diputado general de Galicia], vecino de esta Corte, dos mil reales vellón, por el Retrato que de su orden hice de Su Magestad Reynante, para remitir a colocar en el Grande y Real Hospital de la ciudad de Santiago"24.

22 Pedro RocA, “Autógrafos de D. Pedro Velarte, D. Mariano Álvarez de Castro y D. Francisco de Goya”, Revista de Archivos, Bibliotecas y Museos, 5 (1897), pág. 211.

${ }^{23}$ De los casi trescientos lienzos mencionados en Narciso SENTENACH, Catálogo de los cuadros, escultura, grabados y otros objetos artísticos de la antigua casa ducal de Osuna, expuestas en el palacio de la Industria y de las Artes, $2^{\mathrm{a}}$ ed., Madrid, Viuda e hijos de M. Tello, 1896, aparecen un total de 28 obras adscritas a Goya, pero no los retratos de los monarcas en cuestión encargados al artista por los Duques.

${ }^{24}$ Benavente, “Un retrato ...”, pág. 6; SÁnchez Rivera, Notas Compostelanas..., pág. 243. 


\section{UN “PROTOTIPO” PERDIDO Y}

REENCONTRADO

Si bien la mayoría de estos retratos de Carlos IV se atribuyen a Francisco de Goya, es evidente que se deben -como ya se ha podido suponer-, en mayor o menor medida, al taller de corte, a sus ayudantes y colaboradores más cercanos. Y, por tanto, todo este grupo de retratos se caracteriza por su naturaleza seriada. Según la tesis tradicionalmente defendida por la historiografía desde Sambricio, la cabeza de serie se habría perdido, quedando de ella únicamente las diversas réplicas y copias con variaciones sobre el primer ejemplar original. Pero nada más lejos de la realidad. Merced a la investigación desarrollada por el equipo del Centre d'Art d'Època Moderna (CAEM), recientemente ha sido hallado este

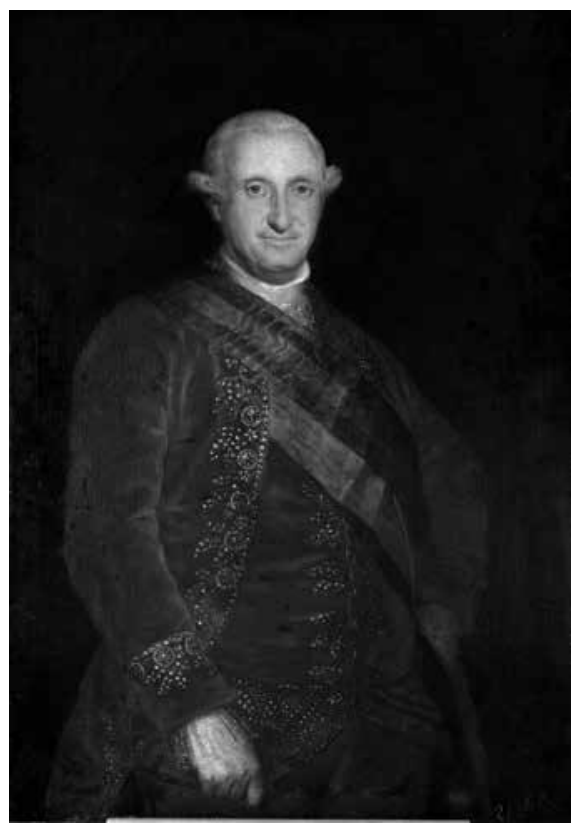

Fig. 5. Francisco de Goya, Carlos IV, 1789, $111,5 \times 76,5 \mathrm{~cm}$, colección particular (en depósito en el Museo Goya-Colección Ibercaja, Zaragoza). (C) CAEM, Universitat de Lleida. prototipo o ejemplar original en una colección particular ${ }^{25}$. Sus orígenes se remontan a la que poseyó Manuel Godoy (1767-1851), en 1808, siendo heredado posteriormente por sus descendientes, y documentado en 1888 en el Palacio de Boadilla del Monte (Madrid) (fig. 5).

La primera mención al retrato se debe al connaisseur francés Frédéric Quilliet, en el inventario que realizó de los bienes de Manuel Godoy, tras la invasión francesa -en enero de 1808-, y ubicados en su palacio de Madrid, conocido como el Almirantazgo ${ }^{26}$. Tras la huida de los franceses en 1813, y antes del regreso de Fernando VII, se ordenó un inventario de la colección de pinturas confiscadas a Godoy. De las piezas que restaban de la colección, aproximadamente un centenar fueron devueltas en 1814 a la condesa de Chinchón y duquesa de Sueca, Carlota Luisa de Godoy y Borbón, hija de Manuel de Godoy y de María

\footnotetext{
${ }^{25}$ Para más información, véase: Isidro PUIG et al., Francisco de Goya. Carlos IV, Lleida, Universitat de Lleida, 2016 (Estudios Monográficos de Pintura, 6).

${ }^{26}$ Frédéric Quilliet, Collection des Tableaux de S.S.S: Le Prince de la Paix, Géné ralissime Grand Amiral, 1808 (AHN, Estado, leg. 3227, núm. 1). Cfr. José Luis SANCHO, "Francisco de Goya y Fréderic Quilliet en el Palacio Real de Madrid, 1808”, Boletín del Museo del Prado, vol. 19, 37 (2001), págs. 115-142.
} 
Teresa de Borbón y Vallabriga, en compensación por los bienes que María Teresa había aportado al matrimonio - procedentes, estos, de la colección heredada de su padre, el infante Don Luis-. En 1814 se realizó otro inventario de los bienes confiscados, los cuales pasaron, finalmente, a ser propiedad de la Academia de San Fernando en 1816. Pero se calcula que alrededor de dos tercios de la colección de pinturas de Manuel Godoy se dispersaron inevitablemente, entre robos, expolios, destrucción, adquisiciones ilegales, exportaciones, etc. ${ }^{27}$.

En 1888, tras el fallecimiento de la Condesa de Chinchón, hija de Godoy, se redactó un "Inventario de los lienzos que formaban la colección de pinturas del Palacio de Boadilla, quedados al fallecimiento de la Excma. Señora Doña Carlota Luisa de Godoy y Borbón Condesa de Chinchón”. En este, según afirma Rose, aparecen una cincuentena de obras que habrían pertenecido en su día a Godoy y, entre ellas, el retrato de Carlos IV que nos ocupa, la cabeza de la serie. Ese inventario de 1888 se realizó con ocasión de la repartición de la heredad a los hijos de la condesa de Chinchón: el III Marqués de Boadilla, Luis Ruspoli y Godoy, y el II Duque de Alcudia, su hermano Adolfo. Los bienes fueron tasados y valorados y cada uno recibió la mitad correspondiente. Pero no hay ningún listado o inventario que señale las obras que heredó cada uno de los herederos.

No obstante, el citado retrato de Carlos IV no era desconocido para la historiografía artística. De hecho, Desparmet ya lo había incluido en su catálogo razonado, y lo situaba en la colección del infante Don Luis de Borbón -es decir, el suegro de Manuel Godoy-. Después estuvo en la colección de la Condesa de Chinchón, en el Palacio de Boadilla del Monte, hasta su fallecimiento en 1886; entonces este y el resto de los cuadros pasaron a su hijo, Adolfo Ruspoli y Godoy, y a su muerte, en 1914, se produjo la definitiva dispersión de la colección. El retrato de Carlos IV se quedó en Madrid, mientras que su pareja, el de la reina María Luisa, tomó rumbo a París ${ }^{28}$.

Poco después, merced al catálogo de la exposición Goya, 1746-1828, celebrada en el Musée des Beaux-Arts de Bordeaux, entre mayo y junio de 1951, se tiene noticia de la pertenencia del susodicho retrato a la colección López Manzas de Madrid; y con anterioridad, en la del marqués de Prado Alegre, también en la capital. Por tanto, resulta altamente probable que tras el fallecimiento de Adolfo Ruspoli el retrato de Carlos IV pasara directamente al marqués de Prado Alegre. Una circunstancia que de momento no podemos afirmar con total certeza. Lo que sí es cierto es que el retrato en cuestión tomó parte en otra exposición en

\footnotetext{
${ }^{27}$ Isadora Rose DE VIEJO, Manuel Godoy patrón de las artes y coleccionista, t. I, Tesis doctoral, Madrid, Universidad Complutense de Madrid, 1983, págs. 348-419.

${ }^{28}$ Xavière Desparmet Fitz-Gerald, L'Oeuvre peint de Goya: catalogue raisonné, vol. II, París, F. de Nobele, 1950, pág. 57, núm. 338, reproducido en plancha 265.
} 
1961: Francisco de Goya, con ocasión del IV centenario de la capitalidad de Madrid. Esta vez, se registra una nueva propiedad y, además, el catálogo deja constancia de la procedencia de la colección de López Manzas ${ }^{29}$.

Por lo que respecta a la autoría y su fortuna crítica, este retrato de Carlos IV ya se dice de Francisco de Goya en el inventario de 1813, en la incautación de los bienes de Godoy por Fernando VII; allí, con el número 8 se refiere "Un cuadro de 4 pies y 6 dedos de alto por 2 pies y 12 dedos de ancho, retrato de Carlos IV, autor D. Francisco Goya" ${ }^{30}$. Años más tarde, en el inventario de 1888 -también conocido como el de Boadilla de 1894-, consta como "N. 218. Goya, Retrato de Carlos $4^{\circ}$ / valor artístico 1000 pesetas, / valor real 500 pesetas" ${ }^{\text {"31 }}$. Es precisamente este número, " 218 ", de color blanco, el que aparece en el extremo inferior derecho del lienzo - una evidencia del todo concluyente, que ha servido para identificarlo como procedente, sin duda, de la colección de Manuel de Godoy-.

Por su parte, Martin-Méry, en la exposición Goya, 1746-1828, data el cuadro hacia 1800 y lo atribuye Goya; la misma autoría que defendió, en 1961, Sambricio en el catálogo de la exposición Francisco de Goya, celebrada, como se ha dicho, en Madrid ${ }^{32}$. En el catálogo revisado por Gassier y Wilson, en 1970, al ocuparse de la pareja de retratos de Carlos IV y su esposa, existentes en el Museo Lázaro Galdiano de Madrid, se aventura que "probablemente fueron pintados por un ayudante" del pintor aragonés; se advertía, además, que una versión de este retrato de Carlos IV estaba localizada en una colección particular madrileña, el cual se había exhibido en la exposición de 1961 -anteriormente citada y donde

\footnotetext{
${ }^{29}$ Valentín de SAmbricio (comis.), Exposición Francisco de Goya. IV Centenario de la Capitalidad [catálogo de exposición], Madrid, Dirección General de Bellas Artes, 1961, pág. 108, cat. CXVIII.

${ }^{30}$ Narciso Sentenach, "Fondos selectos del Archivo de la Academia de San Fernando. La Galería del Príncipe de la Paz", Boletín de la Real Academia de Bellas Artes de San Fernando, año XV, 60 (31 de diciembre 1921), pág. 205.

31 Archivo Histórico Nacional (AHN), fondos, leg. 418. Información también recogida por MuÑOZ Y Manzano, Conde de la Viñaza: Goya: su tiempo, su vida, sus obras, Madrid. Tip. de Manuel G. Hernández, 1887, págs. 220-221, núm. XXIII de su catálogo, cuya descripción es la siguiente: "Retrato de medio cuerpo: viste el Monarca casaca, chupa y calzón de terciopelo encarnado; las dos primeras prendas adornadas con pasamanería y botones en las solapas, mangas y bolsillos. Se ve la mano derecha del retrato medio cubierta por los encajes que salen de la manga de la casaca: el brazo izquierdo descansa sobre la cadera. El peinado es de un solo bucle o rizo. Núm. 218 del citado catálogo". Se le adscribe una pareja, con la representación de la reina María Luisa de Parma, mujer de Carlos IV, con el número de cat. XXII y donde escribe que es el "Núm. 215 del catálogo de las pinturas existentes en el Palacio de Boadilla del Monte, propiedad de la Sra. Duquesa de Sueca, Condesa de Chinchón, D ${ }^{a}$ Carlota Luisa de Godoy y Borbón, cuyo abuelo materno fue el Serenísimo Sr. Infante D. Luis, que tuvo como pintor predilecto y de Cámara a D. Francisco de Goya".

32 Gilberte MARTin-MÉry (comis.), Goya, 1746-1828 [catálogo de exposición], Bordeaux, Musée des Beaux Arts, 1951; SAmBricio (comis.): Exposición Francisco de Goya..., pág. 108.
} 
seguramente pudieron verlo Gassier y Wilson-, y había formado parte también de la colección del Palacio de Boadilla, con el número 218.

Años más tarde, en 1983, Rose catalogó el retrato de Carlos IV que perseguimos como "copia de Goya", sin aventurar ninguna autoría, y desconociendo su paradero, o por lo menos, no dejando constancia de ello ${ }^{33}$. En una publicación más reciente, sin embargo, añadía que mientras la pareja de este cuadro, el retrato de la reina María Luisa de Parma, salió para París hacia 1914, como parte de la herencia del Conde de Moubou de la Rose -a la sazón, descendiente de la condesa de Chinchón-, el otro "continuó en Madrid"34.

\section{EL “ORIGINAL QUE HIZO EL MISMO GOYA”, A LO VIVO}

La datación que se propone para este retrato es principios de 1789, siempre antes de que Goya encargara, en junio del mismo año, los bastidores y materiales para pintar la serie de retratos oficiales, como ya se dijo anteriormente.

Así pues, el susodicho retrato debió ser concebido como prototipo o matriz o, si se prefiere, como boceto provisional sobre el que fueron sucediéndose paulatinos cambios hasta la consecución y fijación definitiva del modelo. Estos cambios y ajustes, naturales en todo proceso creativo, quedaron registrados en el lienzo: recolocación de la figura - cabeza, cuerpo, banda y toisón, brazos y manos-, errores que se enmiendan, fallos de encaje, cambios de punto de vista, etc., formaron parte del proceso de ejecución y, en su mayoría, dejaron alguna huella en las diferentes capas pictóricas. Estas circunstancias resultan de gran importancia, ya que, desde sus mismos inicios, Goya concibió “el borrón como un vehículo de experimentación y de expresión, circunstancia sin duda determinante en la consolidación de la desbordante fantasía creativa de sus últimas creaciones" ${ }^{35}$.

Pero no sería posible estudiar adecuadamente estos cambios, ajustes y arrepentimientos sin aprovechar las posibilidades que ofrecen los análisis físicoópticos no invasivos, que usan radiaciones electromagnéticas tanto visibles fotografía digital con luz transmitida, con luz rasante, macrofotografías- como

\footnotetext{
33 Rose de VIEJo, Manuel Godoy patrón..., pág. 205, cat. 254.

34 Isadora RosE DE VIEJO, "Daños colaterales: la dispersión y destrucción de los cuadros de Goya pintados para Godoy", en Miguel Cabañas Bravo, Amelia López-Yarto Elizalde y Wifredo Rincón García (coords.), Arte en tiempos de guerra, Madrid, Instituto de Historia, CSIC, 2009, pág. 439. El retrato de la reina se cataloga e ilustra en GudIOL, Goya: 1746-1828..., vol. I, págs. 283-284, cat. 307; vol. III, pág. 379, fig. 437.

35 José Manuel De la Mano, "La idea sobre el lienzo: Gestación, función y destino del boceto en Goya y sus contemporáneos”, en Goya y Maella en Valencia. Del Boceto al Cuadro de Altar [catálogo de exposición], Valencia, Generalitat Valenciana, 2002, pág. 43.
} 
invisibles al ojo humano, tal es el caso de la fotografía digital infrarroja (IR) y la radiografía $(\mathrm{RX})$.

En concreto, la reflectografía infrarroja aprovecha la diferente absorbancia y transmitancia de los pigmentos, en longitudes de ondas entre los 900 y los $1600 \mathrm{~nm}$. La imagen obtenida es el resultado de la reflexión parcial de la luz del espectro visible sobre la capa de preparación blanca de la pintura, permitiendo la visualización de estratos subyacentes que se muestran ocultos a la luz visible, al registrarse capas más profundas que la capa superficial. Mientras que algunas longitudes de ondas son reflejadas, otras son absorbidas, lo que genera nuevas lecturas del estrato pictórico, permitiendo la observación de trazos ocultos, pinceladas constructivas, encajes y, especialmente, del dibujo subyacente, cuando este se ha efectuado con materiales ricos en carbono o con determinados pigmentos -si el dibujo inicial se realiza con determinados pigmentos o colorantes, o bien si las capas de preparación no reúnen los requisitos para generar reflexión lumínica, este puede ser prácticamente invisible-.

Por consiguiente, el examen reflectográfico ofrecía la posibilidad de documentar los cambios y arrepentimientos que -de hallarlos-deberían ser adscritos al modelo o ejemplar original, es decir, el primer molde en que se fabricó la figura de tres cuartos del rey Carlos IV realizado por Goya. Habida cuenta de que esta primera versión, en que el pintor aragonés debió tener al rey delante, con total seguridad, conservaría evidencias de las diferentes fases o etapas de ejecución, tales como trazos de dibujo, arrepentimientos o cambios en la composición, resultado de una continua revisión, modificación y adaptación, hasta encontrar la posición y el acabado correctos de la figura.

Así las cosas, en diversos exámenes infrarrojos se advirtió de modo muy nítido una serie de modificaciones o arrepentimientos, que podrían ser clave para la comprensión y correcta interpretación de esta obra. Analicemos en qué consistieron. Para empezar, la reflectografía permitió detectar la posición original de la gorguera: el reborde del cuello, y también la adición de un corbatín de gasa, que solo se ve en parte, pues fue cubierto por la banda de la orden de Carlos III. También se aprecian cambios de posición de las otras dos bandas - de las órdenes napolitana de San Jenaro y francesa del Saint-Esprit-, bajo esta, y, de un modo particular, las modificaciones de la postura de los brazos. De hecho, observamos que la recolocación de la manga del brazo derecho provocó una importante modificación en el dibujo de la decoración de la casaca (fig. 6a).

De igual modo, el estudio radiológico realizado al cuadro fue de gran ayuda para conocer con mayor nitidez la naturaleza de estos añadidos o arrepentimientos, caracterizar algunos materiales y/o procedimientos técnicos y para observar con mayor claridad -lo cual aún es más importante- las imágenes subyacentes. La radiografía forma parte también de las técnicas de análisis con radiaciones 


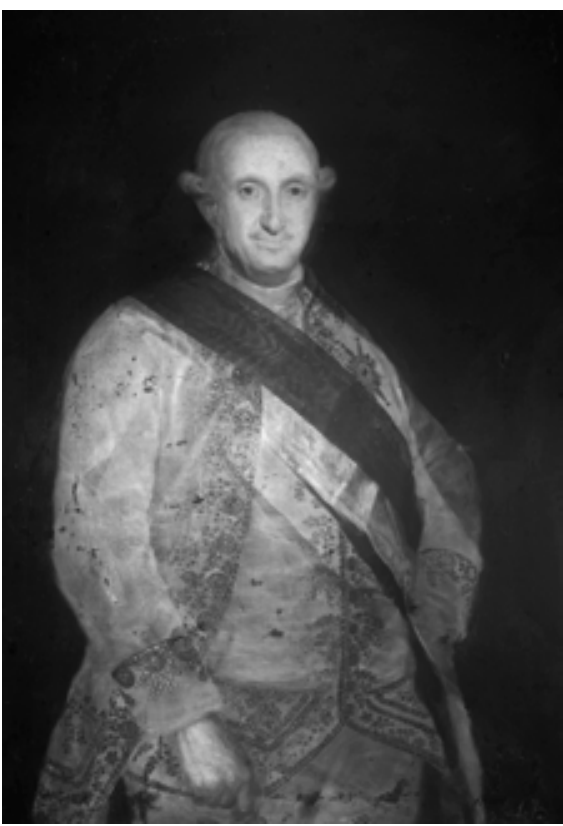

Fig. 6a. Francisco de Goya, Carlos $I V$, $1789,111,5 \times 76,5 \mathrm{~cm}$, colección particular. Fotografía digital infrarroja donde se observa la modificación en la altura de las bandas. (C) CAEM, Universitat de Lleida.

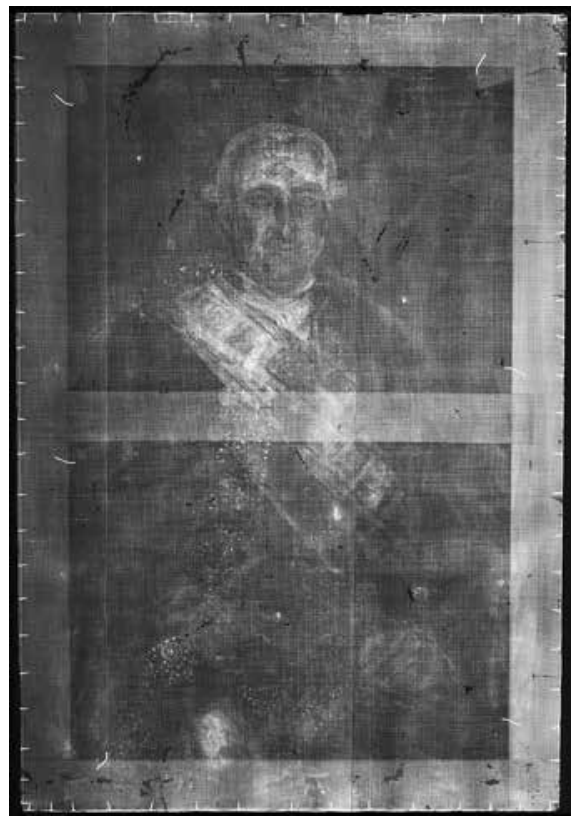

Fig. 6b. Francisco de Goya, Carlos $I V$, 1789, 111,5 x 76,5 cm, colección particular.

Radiografía. Se observan cambios en la posición de la figura, en la banda y el toisón. (C) CAEM, Universitat de Lleida.

de las regiones no visibles del espectro electromagnético, pero, a diferencia de la fluorescencia inducida con luz ultravioleta o la reflectografía infrarroja, presenta una mayor energía y una menor longitud de onda que el resto de técnicas aplicadas. De este modo, las ondas electromagnéticas permiten atravesar los materiales más fácilmente, si bien dependiendo de un mayor o menor grado de resistencia (radiopacidad). No obstante, este método de análisis facilita el examen de las estructuras internas, no visibles ni en la observación directa ni con otros métodos, y permite atravesar todos los estratos que conforman la obra de arte, aportando información simultánea de todos ellos a la vez.

Los rayos X produjeron, sin embargo, una imagen de visión o lectura compleja, con densidades claras y oscuras, una suerte de aguas en el contorno de la figura del rey Carlos IV, debidas tanto a la forma de preparar el lienzo como a lo desigual de su imprimación o al contenido en albayalde -un pigmento radiopaco- de dicha preparación.

No obstante, a través de la imagen radiográfica fue posible documentar también reiteradas modificaciones y alteraciones de la composición inicial, lo que 
permitió hacer un seguimiento de la evolución del cuadro, en cuanto a composición, y organización de la figura, e imaginar cómo la idea inicial del pintor aragonés fue transformándose hasta lograr materializar un modelo del que sentirse satisfecho y poder sacar el mayor partido posible (fig. 6b). El resultado fue una figura con una postura más típica de la retratística goyesca, vuelta ligeramente hacia la derecha, con un torso de mayor enjundia, pero no carente de cierta gracia dinámica por la posición de los brazos, y ocultando, como de costumbre, las manos.

Naturalmente no fue el único de los retratos de la serie sometido a análisis físico-ópticos en las últimas décadas. Cabe recordar que en octubre de 1997 se estudió el retrato de la reina María Luisa de Parma, de la Colección Ibercaja de Zaragoza, en el Gabinete Técnico del Museo del Prado. Según la institución, la radiografía obtenida permitió observar un estadio anterior o subyacente al retrato visible de la soberana, el cual se pretendía fuera el original realizado por el pintor en 1789 y repintado posteriormente, hacia 1799. Por lo tanto, se consideró que Goya lo había pintado "del natural, por lo que probablemente éste era el prototipo, guardado en el taller del que se sacaron las réplicas hoy en día repartidas en varias colecciones" 36 . Esta propuesta fue respaldada por Manuela Mena, quien consideró, además, que dicho retrato y su pareja, conservado en el Museo de Bellas Artes de Oviedo - por tanto, repintados conjuntamente en 1799_37, eran los "dos estudios del natural de los reyes" que Goya había utilizado para reproducir las numerosas copias que salieron del taller de corte ${ }^{38}$.

No obstante, después del estudio comparado de los retratos y de las evidencias físicas $^{39}$, hemos llegado a la conclusión de que estas no pueden ser consideradas pruebas irrefutables de que estamos ante los dos prototipos originales ejecutados por el aragonés entre febrero y abril de 1789. Solo podemos aceptar que, en el caso del ejemplar de Colección Ibercaja -uno más de la serie-, la imagen

\footnotetext{
36 Anna Reuter, "La reina María Luisa”, en La imagen de la mujer. Goya [catálogo de exposición], Madrid, Museo Nacional del Prado, 2002, cat. 62, págs. 246-247.

37 Javier GonzÁLez SANTos, "Francisco Goya y Lucientes. Retrato del rey Carlos IV en traje de corte, 1789; renovado en 1799/1801", en Jovellanos y su entorno en las colecciones del Museo de Bellas Artes de Asturias, Oviedo, Consejería de Cultura y Deporte; Museo de Bellas Artes de Asturias, 2012, cat. 10, págs. 88-93.

38 Manuela MenA, "Carlos IV (1789) / María Luisa de Parma (1789). Francisco de Goya", en El retrato español en el Prado. Del Greco a Goya [catálogo de exposición], Madrid, Museo Nacional del Prado, 2007, págs. 154-155. Propuesta que aprobó anteriormente en "El Rey Carlos IV”, en Goya. Prophet der Moderne [catálogo de exposición], Berlin, Dumont Buchverlag, 2005, cat. 23, págs. 120-124.

${ }^{39}$ Queremos agradecer a la directora del Museo Goya-Colección Ibercaja de Zaragoza, M. ${ }^{\text {a }}$ Rosario Añaños Alastuey, y a la responsable de Relaciones Institucionales de Ibercaja, María José de la Nava Gallardo, el habernos permitido su estudio in-situ el 5 de noviembre de 2014. Así como al director del Museo de Bellas Artes de Oviedo, Alfonso Palacios Álvarez, su amable colaboración al autorizarnos también nuestro examen el 23 de enero de 2015.
} 
de la reina fue conveniente actualizada en algunos de sus detalles, como las insignias o el traje, pero nada más; dado que no presenta cambios en la disposición general de la figura, que por lo demás es un calco perfecto. Por su parte, Anna Reuter apuntó también que "en la radiografía no se aprecia el anterior tocado, que sería como el del retrato de Tabacalera, por lo que es probable que Goya lo pintase de manera tan ligera y abocetada que no pudo detectarse en la toma del Gabinete Técnico del Prado" "40. Es más plausible que este retrato, ya en su misma fase de creación, sufriera algunas modificaciones, a consecuencia de los gustos personales de la reina consorte, quien seguramente no vería con buenos ojos repetir la indumentaria de 1789 y prefería actualizar su imagen a la moda; por ello quizá el tocado original estuviera solamente abocetado, dándosele posteriormente su forma definitiva.

En último lugar, el ejemplar del Museo de Oviedo fue sometido a un examen radiológico en julio de 2010, en el Instituto del Patrimonio Cultural de España (IPCE), ${ }^{41}$ en que no se documentó ningún estadio subyacente o cambio en la composición. Un hecho del que se infiere que no es el prototipo originario de la serie. Además, no se observan variaciones apreciables en las condecoraciones que exhibe en el pecho, ni en la banda de la orden de Carlos III, la cual fue albo de reformas en la distribución de los colores entre 1789 y 1792. Por lo tanto, se trata de un retrato real de una cronología posterior a 1789.

\section{DIBUJO SUBYACENTE Y EVIDENCIAS DE COPIA PICTÓRICA}

Por lo que respecta a las diferentes copias documentadas y/o contratadas por Francisco de Goya, que salieron del taller de Palacio entre 1789 y 1790, es evidente que estas son también resultado del trabajo de sus ayudantes y colaboradores más cercanos, en mayor o menor medida. Y, por tanto, todo este grupo de retratos se caracteriza por responder a una producción artística múltiple o seriada.

No debemos, pues, extrañarnos de que algunos cuadros presenten las mismas medidas, sin apenas variaciones; un ejemplar que custodia el Museo del Prado (P07102), con medidas 127,3 x 94,3 cm; otra réplica, seguramente de mano de Agustín Esteve, y también en el Museo del Prado (P07107), de 127 x 94 cm; el retrato de la Colección Altadis, que guarda el Archivo General de Indias de Sevilla, con medidas 128 x 95,5 cm; o el que es propiedad de la Diputación de A Coruña, actualmente en el Pazo de Raxoi de Santiago, también de 126 x $94 \mathrm{~cm}$. De hecho, merced a los estudios técnicos realizados al retrato de Carlos IV que poseyó Manuel de Godoy, en 1808, y que está en manos privadas, conocemos

\footnotetext{
40 Reuter. "La reina María Luisa", pág. 246.

41 GonZÁlez Santos, “Francisco Goya y Lucientes...”, pág. 90.
} 
más datos sobre el proceso de ejecución de la serie de las efigies regias en su comparación con las copias existentes. No obstante, siguen sin despejarse algunas dudas sobre cómo documentar el procedimiento de copia pictórica.

Parece probable que, a partir de este magnífico "boceto" o prototipo que constituye la cabeza de la serie, se realizaran copias en calco u otro método semejante que permitiera reproducir dos imágenes exactamente iguales en los trazos generales de la composición y en las dimensiones de las figuras; un procedimiento que, sin embargo, podía adaptarse a lienzos de mayores dimensiones, dando lugar incluso a retratos de cuerpo entero, donde simplemente se añadieron las piernas o se recolocó el brazo derecho, si bien manteniendo siempre las proporciones generales del tronco.

En el caso que nos ocupa, parece que Goya no solo utilizó el mismo boceto para la ejecución de las figuras de toda la serie de retratos oficiales, sino que en muchos de ellos reprodujo la misma tipología: Carlos IV viste de terciopelo rojo bordado en plata, y se recorta contra un cortinaje verde que le sirve de fondo, como por ejemplo, en el ejemplar de excelente factura que guarda el Museo del Prado (P07102), procedente del Ministerio de Hacienda, y del cual se conservan otras variantes y copias, de inferior calidad (P07103 y P07104). Ahora bien, cuando se superponen las figuras -respetando la escala original-, los contornos y los trazos generales de la composición coinciden claramente, pese a las diferencias de tamaño de cada lienzo.

Se comprende fácilmente que una copia o réplica - copia sin variaciones-del retrato de un rey debería ser lo más exacta y fiel posible al modelo previamente establecido; algo que, por lo demás, no era difícil. Sabemos que la fidelidad al modelo podía garantizarse, por ejemplo, con el recurso al calco. Esto implicaría necesariamente que en muchas copias debiéramos poder documentar -de ser cierta esta hipótesis - trazos de dibujo, a resultas de la transferencia de líneas de contorno del boceto original al lienzo, especialmente si este fue realizado con materiales ricos en carbono.

Con esta premisa, se realizó la fotografía digital infrarroja del retrato de Carlos IV del antiguo Hospital Real de Santiago de Compostela (fig. 7). Y esta demostró que el retrato fue pintado sin ningún cambio, siguiendo exactamente el modelo original, y ajustándose a la perfección a las dimensiones del boceto. Como era de esperar no se observan ni arrepentimientos ni cambios en la composición general. Además, se advierte nítidamente una línea de contorno que siluetea la cabeza, realizada con un medio fluido -tal vez una tinta-, de trazo grueso en alguna zona, y que evidencia la descarga al final de la línea -observable también a simple vista- en la parte inferior derecha de la barbilla, en su unión con el cuello. Por otro lado, se intuye también el dibujo subyacente en los rasgos fisionómicos básicos, como las cuencas oculares, el párpado superior, las aletas de la nariz, el pliegue buconasal y la comisura de los labios, ejecutado a través 


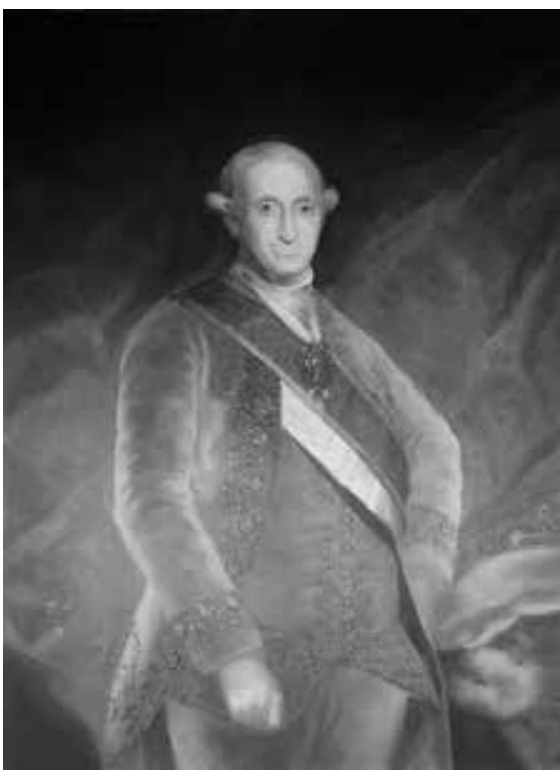

Fig. 7. Francisco de Goya (obrador), El rey Carlos IV, 1790, Diputación de A Coruña. Fotografía digital infrarroja. Se observa la ausencia de arrepentimientos. (C) CAEM, Universitat de Lleida. de un medio sólido -tal vez un calco de carbón-. Y ello a pesar de las limitaciones técnicas, ya que la capacidad de penetración de la fotografía digital infrarroja desde el anverso es reducida - una fotografía infrarroja con luz transmitida seguramente nos proporcionaría mayor información-, así que la calidad de los resultados depende en gran medida del grosor de la capa pictórica. En este caso, afortunadamente, la capa de color es bastante delgada.

Por lo tanto, el sistema de copia utilizado, muy probablemente, fue el calco; recurriendo a una trepa o plantilla, que eventualmente podría haberse desplazado o movido al transferir el dibujo al lienzo, provocando ciertos desajustes de la figura en cuanto al original -perfectamente visibles cuando se superponen las reflectografías infrarrojas de ambos

retratos-. Estos, sin embargo, podrían ser buscados intencionadamente, a fin de estilizar o adelgazar aún más el cuerpo del Rey.

Asimismo, llama poderosamente la atención la presencia de la corona sobre el manto de armiño que cubre la mesa; motivos, ambos, que aparecen y desaparecen en la serie. Estos fueron pintados encima del verde del cortinaje, según confirman los resultados del análisis llevado a cabo por el IPCE, en 1998. Una evidencia que eventualmente indicaría un arrepentimiento, o bien un procedimiento de ejecución a base de superposición de elementos, como resultado de una ejecución rápida, que es lo propio en una producción artística seriada. Esta prisa en la ejecución también es apreciable en la falta de alisamiento de las capas de preparación con piedra pómez u otro abrasivo, como era preceptivo. No obstante, los materiales identificados en las diferentes micromuestras extraídas de los bordes del lienzo se corresponden fielmente con otras pinturas de Goya de ese período, e incluso con la técnica y materiales de otros retratos de la serie ${ }^{42}$.

\footnotetext{
${ }^{42}$ María Teresa Rodríguez Torres, Estudio de los materiales y técnica del Retrato de Carlos IV. Museo del Pueblo Gallego, Santiago de Compostela, estudio técnico inédito, Madrid, 1998 (Instituto del Patrimonio Histórico Español).
} 
En cuanto al proceso de ejecución, todo parece indicar que se empezó por pintar fondo y figura, sobre la base de una imprimación de color rojo anaranjado intenso -fácilmente observable en el examen visual-, reservando el rostro para una fase posterior, de ahí la necesidad técnica de remarcar el contorno con una tinta -quizás tinta metalogálica-, difícilmente cubriente con la mayoría de los pigmentos al uso. Ahora bien, buena parte de los trazos del dibujo deben estar ocultos; es probable que se haya realizado con punta de grafito o plomo y de forma muy suave, quedando así oculto bajo las capas de color más oscuro, o bien bajo las líneas más oscuras que repasan el contorno de la figura. Una posibilidad que impediría documentarlos a través de las técnicas físico-ópticas habituales.

\section{EPÍLOGO}

Tal como recoge el catálogo, en el retrato de Carlos IV del Pazo de Raxoi destaca ese "rostro carente de fuerza y expresión", que es lo propio de una copia $^{43}$; lejos, por tanto, de la viveza que manifiesta el prototipo o ejemplar original que pintó Goya, o de la delicada elaboración de su cara.

Por un lado, cabe destacar que, en el caso de la boca de este retrato, se sigue un patrón técnico similar a las otras pinturas documentadas de Goya, como la de la Colección Altadis o las del Museo del Prado. Observamos una factura relativamente rápida y de modelado sintético, sin embargo, no hace gala de una ejecución excesivamente suelta. La capa pictórica es gruesa y bastante peinada, con pocos empastes frescos, y la configuración de los volúmenes parece quedarse en un estado procesual, casi inacabado; una evidencia más de la apreciable rapidez en la ejecución. En líneas generales, las formas están muy sujetas al dibujo. La escasez de medias tintas y la falta de pequeños detalles de luces y sombras se traducen, por su parte, en la carencia de calidad volumétrica, por lo que la pintura resulta más plana que en las otras copias documentadas de la serie. Esto puede observarse claramente en los labios, en los que se echa en falta un gradiente de sombra en las comisuras, al tiempo que la perfilada línea de separación entre el labio superior y el inferior redunda en la convención.

Por otro lado, los ojos también muestran un trabajo menos minucioso si los comparamos con los otros retratos de la serie y, paradójicamente, pueden observarse las pestañas en el párpado izquierdo, realizadas con media docena de finas pinceladas (fig. 8). El brillo de las pupilas es redondeado y se ubica de manera simétrica en el centro superior de las mismas; el pliegue del surco palpebral apa-

${ }^{43}$ Sobrino y Liaño (dir.), Catálogo..., pág. 646. 


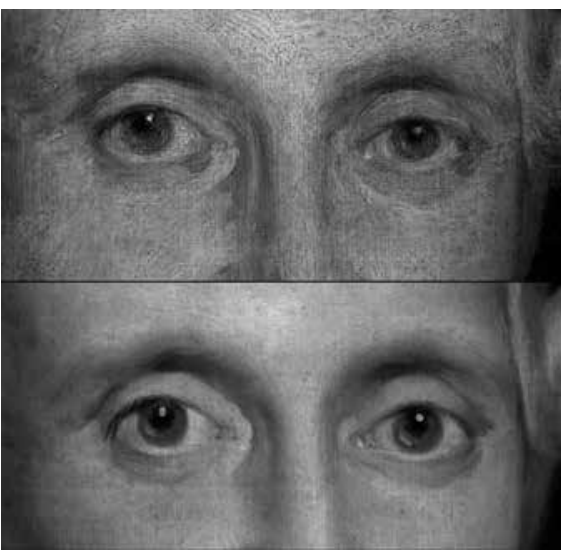

Fig. 8. Estudio comparativo de los detalles de los ojos del retrato de Carlos IV, de colección particular (arriba), y del retrato de Carlos $I V$, de la Diputación de A Coruña (abajo). (C) CAEM, Universitat de Lleida.

rece notablemente remarcado, características ambas que también parecen responder a un cierto convencionalismo.

No obstante, al margen del estudio histórico-artístico, hemos presentado a través de los análisis físico-ópticos $\mathrm{y}$, de un modo particular, de la fotografía digital infrarroja (IR), evidencias del proceso de ejecución que son concluyentes y congruentes, a su vez, con el sistema de copia pictórica utilizado en el taller de Palacio. Por lo demás, solo el prototipo o la cabeza de la serie de retratos de Carlos IV, eventualmente pintado a principios de 1789, ocultaría, en capas subyacentes, toda una serie de cambios en la composición, reajustes y arrepentimientos que - de hallarse- serían prueba de haber sido ejecutado "a lo vivo" por el propio Goya. Hasta la fecha, solo el ejemplar procedente de la antigua colección Godoy, y actualmente en exposición en el Museo Goya-Colección Ibercaja de Zaragoza (desde junio de 2017), reúne -como hemos expuesto en este trabajo- estas evidencias; mientras que su pareja, el prototipo del retrato de María Luisa de Parma, sigue en paradero desconocido.

\section{BIBLIOGRAFÍA}

Benavente, Luís, "Un retrato y un autógrafo de Goya”, $A B C$, [s/n.] (26-07-1934), págs. 6-7.

Burke, Peter, La Fabricación de Luis XIV, Madrid, Nerea, 1995.

Burke, Peter, Visto y no visto. El uso de la imagen como documento histórico, Barcelona, Crítica, 2001.

Camón Aznar, José, Francisco de Goya. Tomo II: 1785-1796, Zaragoza, Caja de Ahorros de Zaragoza, Aragón y Rioja, 1981.

Desparmet Fitz-Gerald, Xavière, L'Oeuvre peint de Goya: catalogue raisonné, vol. II, París, F. de Nobele, 1950.

França, José-Augusto, "Da imagem que falece ao poder: o retrato em Portugal no século XVIII", en Portugal no século XVIII de D. João V à revolução francesa [congreso internacional organizado por la Sociedade Portuguesa de Estudos do século XVIII, Lisboa, 1990], Lisboa, Universitária Editora, 1991. 
França, José-Augusto, “O retrato na época joanina”, en Joanni V Magnifico, A pintura em Portugal ao tempo de D. João V. 1706-1750 [catálogo de exposición], Lisboa, Instituto Português do Patrimônio Arquitectónico e Arqueológico, 1995.

Gasquoine Hartley, Catherine, Spain revisited: a summer holiday in Galicia, London, Stanley Paul \& CO, 1911.

Gasquoine Hartley, Catherine, The story of Santiago de Compostela, London J. M. Dent \& sons, ltd., 1912.

Gassier, Pierre y Wilson, Juliet, Vida y obra de Francisco Goya: reproducción de su obra completa: pinturas, dibujos y grabados, Barcelona, Juventud, 1974.

Goffman, Erving, La presentación de la persona en la vida cotidiana, Buenos Aires; Madrid, Amorrortu; S. C. A, 2006 [primera edición en inglés, 1959].

González Santos, Javier, "Francisco Goya y Lucientes. Retrato del rey Carlos IV en traje de corte, 1789; renovado en 1799/1801", en Jovellanos y su entorno en las colecciones del Museo de Bellas Artes de Asturias, Oviedo, Consejería de Cultura y Deporte; Museo de Bellas Artes de Asturias, 2012, cat. 10, págs. 88-93.

González Zymla, Herbert, Catálogo de pinturas de la Real Academia de la Historia, Madrid, Real Academia de la Historia, 2003.

Gudiol, José, Goya: 1746-1828. Biografia, estudio analítico y catálogo de sus pinturas, Barcelona, Ediciones Polígrafa, 1970, 4 vols.

Mano, José M. de la, "Goya versus Bayeu: de la Proclamación a la Exaltación de Carlos IV", en Francisco Bayeu y sus discípulos [catálogo de exposición], Zaragoza, Cajalón, 2007, págs. 131-160.

Mano, José M. de la, "Hacia las parejas reales de Goya. Evolución de la iconografía oficial de Carlos IV y María Luisa de Parma a través de sus pintores de cámara", Carlos IV. Mecenas y coleccionista [catálogo de exposición], Madrid, Patrimonio Nacional; Sociedad Estatal de Conmemoraciones Culturales, 2009, págs. 75-92.

Mano, José M. de la, "La idea sobre el lienzo: Gestación, función y destino del boceto en Goya y sus contemporáneos", en Goya y Maella en Valencia. Del Boceto al Cuadro de Altar [catálogo de exposición], Valencia, Generalitat Valenciana, 2002, págs. 42-57.

Martin-Méry, Gilberte (comis.), Goya, 1746-1828 [catálogo de exposición], Bordeaux, Musée des Beaux Arts, 1951.

Mena, Manuela, "El Rey Carlos IV”, en Goya. Prophet der Moderne [catálogo de exposición], Berlin, Dumont Buchverlag, 2005, cat. 23, págs. 120-124.

Mena, Manuela, "Carlos IV (1789) / María Luisa de Parma (1789). Francisco de Goya", en El retrato español en el Prado. Del Greco a Goya [catálogo de exposición], Madrid, Museo Nacional del Prado, 2007, págs. 154-155.

Morales y Marín, José Luís, Las parejas reales de Goya. Retratos de Carlos IV y María Luisa de Parma, Zaragoza, Real Academia de Nobles y Bellas Artes de San Luis, 1997.

Muñoz y Manzano, Conde de la Viñaza, Goya: su tiempo, su vida, sus obras, Madrid, Tip. de Manuel G. Hernández, 1887.

Puig, I., et al., Francisco de Goya. Carlos IV, Lleida, Universitat de Lleida, 2016.

Quilliet, Frédéric, Collection des Tableaux de S.S.S: Le Prince de la Paix, Géné ralissime Grand Amiral, 1808 [Manuscrito fechado 1 enero de 1808, localizado en el Archivo Histórico Nacional, Estado, leg. 3227/1]. 
Ramírez y Góngora, Manuel Antonio, Gozo y lealtad con que orla Córdoba la corona de su triunfo en la Real Proclamación de el Rey y Señor D. Carlos Quarto..., Córdoba, imprenta de Don Juan Rodríguez de la Torre, [s.a.].

Reuter, Anna, "La reina María Luisa", en La imagen de la mujer. Goya [catálogo de exposición], Madrid, Museo Nacional del Prado, 2002, cat. 62, págs. 246-247.

Roca, Pedro, "Autógrafos de D. Pedro Velarte, D. Mariano Álvarez de Castro y D. Francisco de Goya", Revista de Archivos, Bibliotecas y Museos, 5 (1897), pág. 211.

Rodríguez Gordillo, José M.; Morales Sánchez, José, y Pérez Sánchez, Alfonso E., Goya. Retratos para la Real Fábrica de Tabacos de Sevilla, Madrid, Tabapress para Tabacalera S. A., 1985.

Rodríguez Torres, María Teresa, Estudio de los materiales y técnica del Retrato de Carlos IV. Museo del Pueblo gallego, Santiago de Compostela, estudio técnico inédito, Madrid, 1998.

Rose de Viejo, Isadora, "Daños colaterales: la dispersión y destrucción de los cuadros de Goya pintados para Godoy", en Miguel Cabañas Bravo, Amelia López-Yarto Elizalde y Wifredo Rincón García (coords.), Arte en tiempos de guerra, Madrid, Instituto de Historia, CSIC, 2009, págs. 433-443.

Rose de Viejo, Isadora, Manuel Godoy patrón de las artes y coleccionista, t. I, Tesis doctoral, Universidad Complutense de Madrid, 1983.

Sambricio, Valentín de (comis.), Exposición Francisco de Goya. IV Centenario de la Capitalidad [catálogo de exposición], Madrid, Dirección General de Bellas Artes, 1961.

Sambricio, Valentín de, "Los retratos de Carlos IV y María Luisa, por Goya", Archivo Español de Arte, t. 30, núm. 118 (1957), págs. 85-113.

Sambricio, Valentín de, Tapices de Goya, Madrid, Patrimonio Nacional, 1946.

Sánchez Rivera, Ceferino, Notas Compostelanas. Historia. Tradiciones. Leyendas. Miscelánea, Santiago de Compostela, Libreria y Editorial Sucesores de Galí, s/f (h. 1945).

Sancho, José Luís, "Francisco de Goya y Fréderic Quilliet en el Palacio Real de Madrid, 1808", Boletín del Museo del Prado, vol. 19, 37 (2001), págs. 115-142.

Sempere y Guarinos, Juan, Descripción de los ornatos públicos con que la Corte de Madrid ha solemnizado la feliz exaltación al trono de los reyes ... Don Carlos IIII y Doña Luisa de Borbón, y la jura del Serenísimo Señor Don Fernando, Príncipe de Asturias, Madrid, Imprenta Real, 1789.

Sentenach, Narciso, "Fondos selectos del Archivo de la Academia de San Fernando. La Galería del Príncipe de la Paz", Boletín de la Real Academia de Bellas Artes de San Fernando, año XV, 60 (31 de diciembre 1921), págs. 204-211.

Sentenach, Narciso, Catálogo de los cuadros, escultura, grabados y otros objetos artísticos de la antigua casa ducal de Osuna, expuestas en el palacio de la Industria y de las Artes, $2^{\mathrm{a}}$ ed., Madrid, Viuda e hijos de M. Tello, 1896.

Sobrino, María Luisa y Liaño, María Dolores (dir.), Catálogo del Patrimonio Artístico de la Diputación de A Coruña. I: Pintura y Escultura, A Coruña, Diputación Provincial, 1991.

Soria, Martín de, “Agustín Esteve and Goya", The Art Bulletin, vol. 25, 3 (1943), págs. 239266.

Soria, Martín de, Agustín Esteve y Goya, Valencia, Institución Alfonso el Magnánimo, Diputación Provincial de Valencia, 1957.

Tormo, Elías, La visita a las colecciones artísticas de la Real Academia de San Fernando, Madrid, Hauser y Menet, 1929. 